\title{
PENGUKURAN KOEFISIEN ABSORBSI MATERIAL AKUSTIK DARI SERAT ALAM AMPAS TEBU SEBAGAI PENGENDALI KEBISINGAN
}

\author{
Fajri Ridhola, Elvaswer \\ Laboratorium Fisika Material, Jurusan Fisika FMIPA Universitas Andalas \\ Kampus Unand, Limau Manis, Padang, 25163 \\ e-mail:fajri_ridhola@yahoo.com
}

\begin{abstract}
ABSTRAK
Telah dilakukan penelitian tentang pengukuran koefisien absorbsi material akustik dari serat alam ampas tebu sebagai pengendali kebisingan. Metode yang digunakan yaitu metode tabung. Komposit berbahan dasar serat ampas tebu dengan matriks resin poliester-MEKPO. Komposit tersebut dibuat dengan massa serat berbeda dan massa resin poliester sama pada setiap sampel yaitu 60 g. Sampel 1 dengan massa serat 0,4 g, sampel 2 dengan massa serat 0,6 g, sampel 3 dengan massa serat $0,8 \mathrm{~g}$, sampel 4 dengan massa serat $1 \mathrm{~g}$ dan sampel 5 dengan massa serat 1,2 $\mathrm{g}$. Range frekuensi yang digunakan pada penelitian ini yaitu $500 \mathrm{~Hz}, 1000 \mathrm{~Hz}, 2000 \mathrm{~Hz}, 4000 \mathrm{~Hz}$ dan $8000 \mathrm{~Hz}$. Hasil penelitian menunjukkan bahwa nilai koefisien absorbsi bunyi pada sampel ke 4 paling tinggi terjadi pada frekuensi $1000 \mathrm{~Hz}$ yakni 0,961 dan sampel ke 5 memiliki nilai koefisien absorbsi paling rendah pada frekuensi $500 \mathrm{~Hz}$ dengan nilai 0,363. Nilai impedansi akustik tertinggi terjadi pada sampel ke 4 yaitu pada frekuensi $8000 \mathrm{~Hz}$ dengan nilai 0,9774 dyne.s $/ \mathrm{cm}^{5}$. Serat ampas tebu ini sangat cocok digunakan pada ruangan audio karena memiliki nilai koefisien absorbsi yang cukup tinggi pada frekuensi $1000 \mathrm{~Hz}$.
\end{abstract}

Kata kunci : koefisien absorbsi, impedansi akustik, serat ampas tebu, resin poliester-MEKPO, matriks, frekuensi

\section{PENDAHULUAN}

Penggunaan mesin dan teknologi di bidang insdustri akan menimbulkan efek kebisingan. Kebisingan adalah salah satu masalah yang perlu diperhatikan. Pentingnya kenyamanan akustik suatu ruangan sangat ditentukan oleh beberapa faktor diantaranya pemilihan bahan penyerap suara yang baik. Kebisingan dapat dikendalikan dengan menggunakan berbagai bahan material akustik. Penggunaan material akustik yang tepat dapat meredam kebisingan. Bahan yang digunakan bisa berasal dari serat sintetis dan serat alam.

Jenis bahan penyerap suara yang akan digunakan yaitu serat alam berpori berbentuk panel, dimana bahan tersebut dari serat alam ampas tebu. Serat alam ampas tebu (bagasse) adalah bahan limbah berserat yang telah mengalami ekstraksi, sehingga ampas tebu ini dapat memenuhi persyaratan diolah menjadi papan panel (Indriani dan Sumiarsih, 1992). Pemanfaatan bahan serat ampas tebu ini sangat jarang dimanfaatkan. Selain itu upaya pemanfaatan produk dari serat ampas tebu untuk meningkatkan nilai tambah dari limbah ampas tebu dan mengurangi polusi limbah padat.

Farid, dkk. (2012) melakukan penelitian mengenai serat tebu sebagai penyerap akustik berkelanjutan. Dari hasil penelitiannya diketahui kinerja akustik penyerap tebu dengan ketebalan 1,25 cm dengan koefisien absorbsi rata-rata 0,65 pada frekuensi 1,2 sampai 4,5 KHz. Kartikaratri, dkk. (2012) telah melakukan penelitian mengenai pembuatan komposit serat serabut kelapa dan resin fenol formadehide sebagai material peredam akustik. Hasil penelitian diketahui serabut kelapa memenuhi persyaratan untuk peredam suara dengan nilai koefisien absorbsi 0,94 pada jangkauan frekuensi 752 sampai $6400 \mathrm{~Hz}$. 
Komposit adalah campuran dua bahan atau lebih yang memiliki sifat yang berbeda. Secara umum penyusun komposit tersusun dari pengikat (matriks) dan material penguat (reinforcement). Bahan komposit juga mempunyai kestabilan mekanik yang baik karena terjadi ikatan antara dua bahan tersebut. Komposit mempunyai banyak keunggulan dibandingkan dengan bahan lain misalnya bahan tunggal diantaranya serat komposit memiliki massa yang lebih ringan karena komposit merupakan bahan yang terdiri atas penguat dan matriks dengan massa yang berbeda (Wirajaya, 2007). Material akustik merupakan komposit yang terdiri dari matrik dan penguat. Matrik yang banyak digunakan oleh para peneliti adalah jenis polimer. Polimer yang digunakan sebagai matriknya adalah resin poliester dan katalis MEKPO (methyl ethyl ketone peroxide). Resin poliester adalah suatu material yang berbentuk cairan pada suhu ruang atau berupa material padatan yang dapat meleleh pada suhu di atas $200^{\circ} \mathrm{C}$. Pada dasarnya resin poliester adalah matriks, sehingga memiliki fungsi yang sama dengan matriks (Surdia dan Saito, 1995).

Penelitian ini, dilakukan untuk menentukan nilai koefisien absorbsi bunyi dan impedansi akustik dari campuran material serat ampas tebu dengan resin poliester-MEKPO. Pengujian akustik dapat dibedakan berdasarkan tempat pengujiannya yakni pengujian di dalam tabung dua mikrofon dan pengujian dalam ruang dengung (Doelle, 1993). Pada penelitian penentuan koefisien absorbsi akustik dilakukan dengan menggunakan metode tabung. Metode tabung dipilih karena praktis dan material yang diperlukan relatif sedikit dibandingkan dengan metode ruang dengung dan metode tabung dua mikrofon. Koefisien absorbsi bunyi dinyatakan dalam bilangan antara 0 sampai 1 . Nilai koefisien serapan 0 menyatakan tidak ada energi bunyi yang diserap dan nilai koefisien serapan 1 menyatakan serapan yang sempurna (Doelle, 1993). Pada metode tabung penentuan koefisien absorbsi bunyi dilakukan dengan menghitung perbandingan amplitudo tekanan maksimum dengan amplitudo tekanan minimumnya. Perbandingan amplitudo tekanan ini dinamakan rasio gelombang tegak (Standing Wave Ratio, SWR). Secara matematis nilai rasio gelombang tegak dapat dinyatakan pada Persamaan 1.

$$
S W R=\frac{A+B}{A-B}
$$

Dengan $A+B$ adalah amplitudo tekanan maksimum, $A-B$ adalah amplitudo tekanan minimum.

Sedangkan koefisien absorbsi bunyi $(\alpha)$ dapat ditentukan dari Persamaan 2.

$$
\alpha=1-\left(\frac{S W R-1}{S W R+1}\right)^{2}
$$

Dengan $S W R$ adalah rasio gelombang tegak.

Impedansi akustik dihitung dengan menggunakan Persamaan 3.

$$
\frac{Z_{s}}{\rho_{c}}=\operatorname{coth}\left(\psi_{1}+\psi_{2}\right)
$$

Dengan $Z_{s}$ adalah impedansi akustik (dyne.s $/ \mathrm{cm}^{5}$ ). $\rho_{c}$ adalah impedansi karakteristik udara. Untuk dapat menentukan impedansi akustik terlebih dahulu harus ditentukan nilai $\Psi_{1}$ dan $\Psi_{2}$ yang dapat dinyatakan pada Persamaan 4 dan Persamaan 5.

$$
\psi_{1}=\operatorname{coth}^{-1}\left(\log _{10}{ }^{-1}(S W R / 20)\right)
$$




$$
\psi_{2}=\pi\left(\frac{1}{2}-\frac{d_{1}}{d_{2}}\right)
$$

$\Psi_{1}, \Psi_{2}$ adalah bilangan kompleks, $d_{1}$ adalah jarak amplitudo minimum pertama $(\mathrm{cm})$ dan $d_{2}$ adalah jarak amplitudo dari minimum pertama ke minimum kedua $(\mathrm{cm})$.

\section{METODE}

\subsection{Pembuatan Komposit Serat Ampas Tebu}

Awal pembuatanya yaitu serat ampas tebu diambil dari salah satu tempat penggilingan tebu dan dicuci bersih dengan air terlebih dahulu. Kemudian dikeringkan dengan bantuan sinar matahari selama 5 hari. Selanjutnya serat ampas tebu dimasukkan ke dalam oven dengan temperatur $70^{\circ} \mathrm{C}$ selama 2 jam. Setelah proses pengeringan, ampas tebu dipisahkan menggunakan sikat besi untuk mendapatkan serat yang dibutuhkan. Setelah serat ampas tebu dipisahkan, kemudian serat ampas tebu dipotong dengan ukuran $3 \mathrm{~cm}$. Teknik yang digunakan untuk membuat sampel material akustik menggunakan teknik sandwich dimana komposit ini tersusun dari tiga lapis yaitu resin sebagai permukaan dan penutup komposit, serta serat ampas tebu sebagai material inti di bagian tengah. Sampel yang dibuat sesuai dengan ukuran tabung dengan panjang $125 \mathrm{~cm}$ dan diameter $8 \mathrm{~cm}$ dengan massa resin sama yaitu $60 \mathrm{~g}$. Massa matrik dan serat ditunjukkan oleh Tabel 1.

Tabel 1 Perbandingan massa serat ampas tebu dengan matriks resin poliester-MEKPO

\begin{tabular}{|c|c|c|}
\hline Sampel & Matriks $(\mathrm{g})$ & Serat $(\mathrm{g})$ \\
\hline 1 & 60 & 0,4 \\
\hline 2 & 60 & 0,6 \\
\hline 3 & 60 & 0,8 \\
\hline 4 & 60 & 1,0 \\
\hline 5 & 60 & 1,2 \\
\hline
\end{tabular}

\subsection{Pengujian menggunakan Tabung Impedansi}

Pengujian ini dilakukan dengan tabung impedansi untuk mengetahui kemampuan material komposit serat ampas tebu dalam menyerap bunyi. Tabung impedansi digunakan karena pengoperasiannya lebih mudah dan material uji memiliki ukuran yang cukup kecil, sesuai dengan ukuran tabung. Tabung impedansi yang akan digunakan terbuat dari besi yang dirangkai sedemikian rupa. Dalam pengoperasiannya tabung impedansi ini dihubungkan dengan beberapa alat antara lain yaitu amplifier, osiloskop, generator sinyal, catu daya, mikrofon dan loudspeaker. Skema rangkaian tabung impedansi dapat dilihat pada Gambar 1.

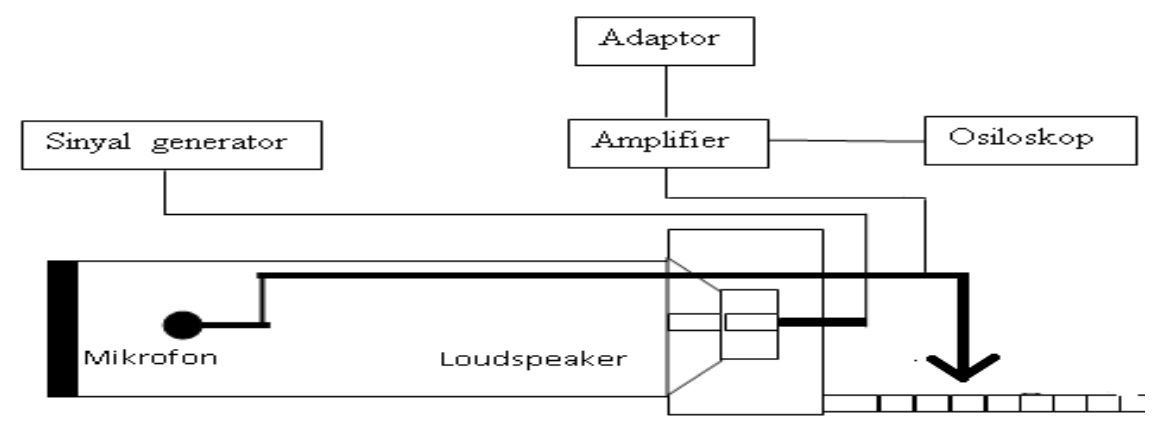

Gambar 1 Skema rangkaian tabung impedansi 
Pada pengujian, bunyi dihasilkan oleh sinyal generator yang dihubungkan dengan loudspeaker. Pada salah satu ujung tabung diletakkan loudspeaker, pada ujung tabung yang lain diletakkan sampel yang akan diuji nilai koefisien absorbsinya. Mikrofon diletakkan di tengah-tengah diameter tabung menghadap ke sampel material akustik. Mikrofon dihubungkan dengan sebuah kawat sehingga dapat digeser untuk menentukan amplitudo tekanan maksimum dan amplitudo tekanan minimumnya. Mikrofon diperkuat dengan amplifier dan dihubungkan ke osiloskop untuk menampilkan bentuk gelombang yang akan dihitung amplitudo tekanan maksimum dan minimumnya. Frekuensi yang digunakan adalah frekuensi pada oktaf-band, yaitu $500 \mathrm{~Hz}, 1000 \mathrm{~Hz}, 2000 \mathrm{~Hz}, 4000 \mathrm{~Hz}$ dan $8000 \mathrm{~Hz}$ (Doelle, 1993).

\section{HASIL DAN DISKUSI}

\subsection{Pengaruh frekuensi terhadap koefisien absorbsi bunyi}

Pada Gambar 2 dapat dilihat bahwa pada frekuensi $500 \mathrm{~Hz}$ untuk setiap sampel, nilai koefisien absorbsi bunyinya bernilai rendah jika dibandingkan dengan frekuensi lainnya yang lebih tinggi. Hal ini disebabkan karena pada frekuensi rendah, gelombang bunyi yang merambat di dalam tabung memiliki panjang gelombang $(\lambda)$ yang panjang sehingga gelombang yang dipantulkan lebih besar dibandingkan gelombang diserap oleh material.

Koefisien absorbsi bunyi paling tinggi terjadi pada sampel 4 dengan frekuensi $1000 \mathrm{~Hz}$ yang bernilai 0,961, kemudian menurun pada frekuensi $2000 \mathrm{~Hz}$. Hal ini disebabkan frekuensi $1000 \mathrm{~Hz}$ merupakan frekuensi optimum dimana pada frekuensi tersebut terjadi pembuangan energi pada sampel mengakibatkan terjadinya peningkatan koefisien absorbsi bunyi (Sinaga, dkk., 2012). Pada frekuensi $2000 \mathrm{~Hz}$ koefisien absorbsinya menurun, hal ini disebabkan material akustik cenderung bersifat resesif dimana mengalami penurunan koefisien absorbsi bunyi pada frekuensi tertentu.

Pada frekuensi $4000 \mathrm{~Hz}$ terjadi peningkatan koefisien absorbsi bunyi kecuali pada sampel 1. Hal ini disebabkan terjadinya interferensi konstruktif pada frekuensi tersebut, mengakibatkan koefisien absorbsi meningkat (Sinaga, dkk., 2012). Nilai koefisien absorbsi bunyi mengalami penurunan yang tidak terlalu signifikan pada frekuensi 8000 $\mathrm{Hz}$.

Sampel 4 menunjukkan koefisien absorbsi bunyi tertinggi kecuali pada frekuensi 2000 Hz. Hal ini disebabkan pada sampel 4 mempunyai komposisi serat paling optimum, menyebabkan gelombang lebih mudah diserap oleh bahan yang dapat meningkatkan nilai koefisien absorbsinya.

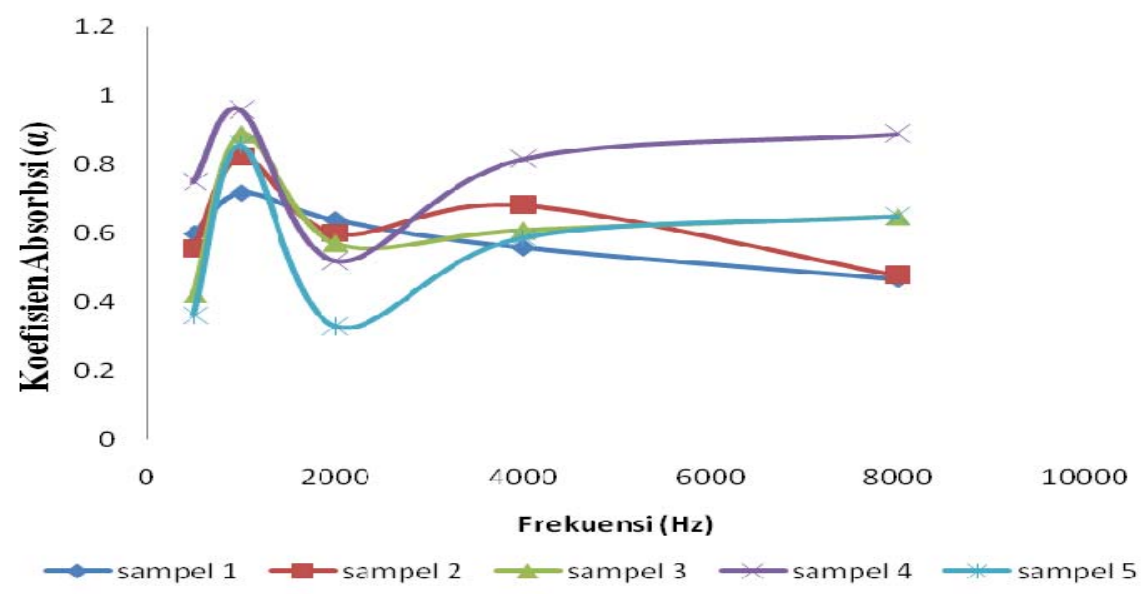

Gambar 2 Hubungan koefisien absorbsi bunyi $(\alpha)$ pada material serat alam ampas tebu terhadap frekuensi $(\mathrm{Hz})$. 


\subsection{Pengaruh frekuensi terhadap impedansi akustik}

Dari Gambar 3 dapat dilihat nilai impedansi akustik tertinggi terjadi pada frekuensi 1000 $\mathrm{Hz}$ dengan nilai impedansi akustiknya 0,9698 dyne. $\mathrm{s} / \mathrm{cm}^{5}$ dan nilai impedansi akustik terendah terdapat pada frekuensi $4000 \mathrm{~Hz}$ dengan nilai 0,6331 dyne.s $/ \mathrm{cm}^{5}$. Pada sampel 2 dan 3 impedansi akustik tertinggi terdapat pada frekuensi $2000 \mathrm{~Hz}$, tetapi pada frekuensi $4000 \mathrm{~Hz}$ terjadi penurunan impedansi akustik menjadi 0,8700 dyne.s $/ \mathrm{cm}^{5}$ dan 0,8578 dyne.s $/ \mathrm{cm}^{5}$, dan mengalami peningkatan nilai impedansi akustik pada frekuensi $8000 \mathrm{~Hz}$. Pada sampel 4 dan 5 impedansi tertinggi terdapat pada frekuensi $8000 \mathrm{~Hz}$. Sampel ke 4 memiliki nilai impedansi terendah pada frekuensi $500 \mathrm{~Hz}$ dengan nilai impedansi akustiknya 0,8717 dyne.s $/ \mathrm{cm}^{5}$ sedangkan sampel ke 5 memiliki impedansi akustik terendah pada frekuensi $4000 \mathrm{~Hz}$ dengan nilai impedansi akustiknya 0,8246 dyne.s $/ \mathrm{cm}^{5}$.

Dari data yang diperoleh, dapat diketahui bahwa nilai impedansi akustik bergantung pada frekuensi dan massa serat, dimana semakin bertambahnya massa serat dan frekuensi, maka impedansi akustik akan semakin tinggi seperti terdapat pada sampel 4 dan 5 . Tetapi, pada sampel 1, 2 dan 3 tidak berlaku, disebabkan massa serat dan matrik dari sampel yang kurang optimum.

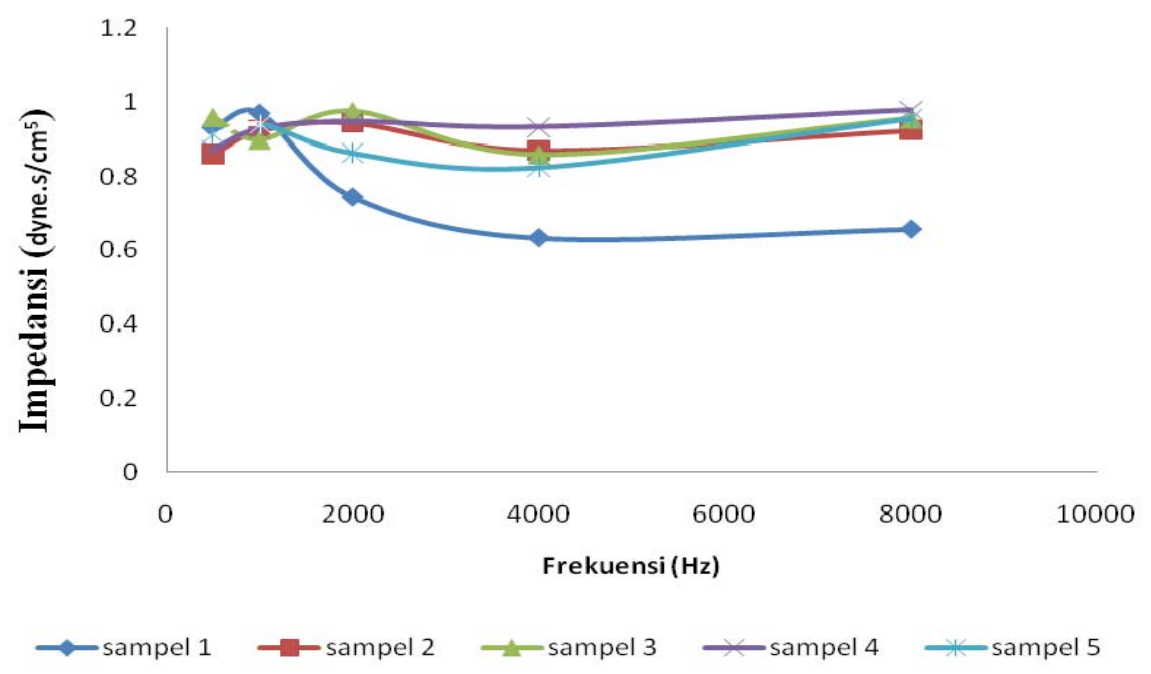

Gambar 3 Hubungan impedansi akustik terhadap frekuensi (Hz)

\section{KESIMPULAN}

Koefisien absorbsi bunyi tertinggi yaitu 0,961 pada frekuensi $1000 \mathrm{~Hz}$ didapatkan pada sampel ke 4 dengan massa serat ampas tebu $1 \mathrm{~g}$. Nilai impedansi akustik tertinggi yaitu 0,9774 dyne.s $/ \mathrm{cm}^{5}$ pada frekuensi $8000 \mathrm{~Hz}$ terdapat pada sampel 4. Serat ampas tebu ini sangat cocok digunakan pada ruangan audio karena memiliki nilai koefisien absorbsi bunyi yang cukup tinggi pada frekuensi $1000 \mathrm{~Hz}$.

\section{DAFTAR PUSTAKA}

1. Doelle, E. dan Leslie, L., 1993, Akustik Lingkungan, Erlangga, Jakarta.

2. Farid, M., Putra, A., Abdullah, Y., Efendy, H., Ayob, R., dan Sajidin, M., 2013, Untilizing Sugarcane Wasted Fibers As A Sustanable Acoustic Absorber, Procedia Engineering, Volume 53, Elsevier, hal 632-638.

3. Indriani, H. dan Sumiarsih, E., 1992, Budidaya Pengelolaan dan Pemasaran Rumput Laut, Penebar Swadaya, Jakarta. 
4. Kartikaratri, Y. M., Agus, S., dan Hendri, W., 2012, Pembuatan Komposit Serat Serabut Kelapa Dan Resin Fenol Formadehide Sebagai Material Peredam Akustik, Jurnal Berkala Fisika, Vol. 15, No. 3, UNDIP, hal 87-90.

5. Sinaga, D., Defriyanto, I., dan Krisman, M., Pengukuran koefisien Absorbsi Bunyi dari Limbah Batang Kelapa Sawit, Jurnal Fisika, UNRI, vol. 9, No. 5, hal 415-423.

6. Surdia, T. dan Saito, S., 1995, Pengetahuan Bahan Teknik, PT Pradnya Paramita, Jakarta.

7. Wirajaya, A., 2007, Karakteristik Komposit Sandwich Serat Alami sebagai Absorber Suara, Tesis Program Magister, Sekolah Pasca Sarjana, ITB, Bandung. 